\title{
Selective gene silencing by viral delivery of short hairpin RNA
}

\author{
Katja Sliva*, Barbara S Schnierle
}

\begin{abstract}
RNA interference (RNAi) technology has not only become a powerful tool for functional genomics, but also allows rapid drug target discovery and in vitro validation of these targets in cell culture. Furthermore, RNAi represents a promising novel therapeutic option for treating human diseases, in particular cancer. Selective gene silencing by RNAi can be achieved essentially by two nucleic acid based methods: i) cytoplasmic delivery of short doublestranded (ds) interfering RNA oligonucleotides (siRNA), where the gene silencing effect is only transient in nature, and possibly not suitable for all applications; or ii) nuclear delivery of gene expression cassettes that express short hairpin RNA (shRNA), which are processed like endogenous interfering RNA and lead to stable gene downregulation. Both processes involve the use of nucleic acid based drugs, which are highly charged and do not cross cell membranes by free diffusion. Therefore, in vivo delivery of RNAi therapeutics must use technology that enables the RNAi therapeutic to traverse biological membrane barriers in vivo. Viruses and the vectors derived from them carry out precisely this task and have become a major delivery system for shRNA. Here, we summarize and compare different currently used viral delivery systems, give examples of in vivo applications, and indicate trends for new developments, such as replicating viruses for shRNA delivery to cancer cells.
\end{abstract}

\section{Introduction}

The human genome project not only unraveled the human genetic code, but spin-off technical improvements also inspired genome sequencing of a multitude of other organisms. However, since sequence data alone are not sufficient to identify gene function, gene knockout or knock-in strategies have to replenish the results in order to analyze the resulting phenotypic changes defining gene functions.

Knowledge about the in vivo phenotype after knocking out gene products is a prerequisite to assess the therapeutic potential of inhibitors against specific targets, so in drug development knock-out animal models have become very important. However, generating transgenic animals is still very labor and cost intense. Alternatively, selective silencing can be achieved by exploiting the RNA interference (RNAi) machinery of the host cell.

Since its discovery by Fire and Mello [1] in C. elegans in 1998, which gained them the Nobel prize in 2006, and by Tuschl et al. [2] in mammalian cells in 2001, RNAi was quickly adopted by the research community

\footnotetext{
*Correspondence: slika@pei.de

\section{() Biomed Central}

Paul-Ehrlich-Institute, Paul-Ehrlich-Str. 51-59, 63225 Langen, Germany as a versatile tool with a wide range of applications, from reverse genetics to high throughput screening of drug targets. The key therapeutic advantage of using RNAi lies in its ability to specifically and potently knock-down the expression of disease-causing genes of known sequence.

Although RNAi is in comparison to knock-out strategies, able to only knock-down the gene expression, simple in vivo inhibition of single gene products by RNAi yields phenotypes that are comparable to classical knock-out animals used for therapeutic target identification or validation. Furthermore, basic research benefits from in vivo RNAi as this strategy can be changed dependent on the desired outcome. For example, conditional gene knock-outs utilizing inducible promoters can be used to unravel molecular pathways and investigate functional genomics.

RNAi is a basic pathway in eukaryotic cells. In contrast to activating cascades in cells upon exposure to long double stranded RNA, leading to non-specific RNA degradation, RNAi is mediated by short RNA duplexes hitchhiking a cellular pathway that silences genes in a sequence-specific manner at the mRNA level. Perfectly complementary dsRNA (short hairpin RNA, shRNA) is 
chopped up by Dicer, a ribonuclease III (RNase III) family member, into small interfering RNA (siRNA) duplexes 21-23 nt in length with symmetric 2-3 nucleotide (nt) 3' overhangs [3]. The use of siRNA duplexes is often accompanied by off-target effects, which can be avoided or reduced by adding backbone modifications to the duplexes to alter key thermodynamic and binding properties [4-7]. DICER-chopped duplexes are incorporated into a protein complex called the RNA-induced silencing complex (RISC) and subsequently unwound by the multi-functional protein Argonaut 2, contained within RISC. The activated RISC, which contains the antisense strand (or guide strand) of the siRNA, is then thought to direct the siRNA to the target mRNA with identical sequence. This leads to degradation of the target mRNA. The activated RISC complex can then move on to destroy additional mRNA targets, which further propagates gene silencing $[8,9]$. This feature of the RNAi mechanism induced by synthetic siRNA provides a knock-down effect for up to seven days in rapidly dividing cells and for several weeks in resting cells $[10,11]$. Thus, RNAi provides a simple, inexpensive and selective method for gene inhibition with a high success rate [12].

Eukaryotes produce various types of small RNAs that function in diverse pathways [3,13-15]. Since in some species the active forms of small RNAs are often indistinguishable biochemically or functionally, they are conventionally grouped into two classes based on their origins and their biogenesis: microRNAs (miRNAs) and small interfering RNAs (siRNAs). MiRNAs are generated from the dsRNA region of the hairpin-shaped precursors, whereas siRNAs are derived from long double-stranded RNAs (dsRNAs) [16]. MiRNAs are transcribed as primary miRNA transcripts (pri-miRNAs) which are then processed within the nucleus by a complex consisting of RNAse III enzyme Drosha and the double-stranded RNAbinding protein DGCR 8 into pre-miRNAs. These are exported from the nucleus into the cytoplasm by exportin5. In the cytoplasm the pre-miRNA enters the same pathway as the above mentioned siRNA. At the end both miRNAs and siRNAs bind to mRNA and induce mRNA cleavage, translational repression, and cleavage-independent mRNA decay [17]. While miRNAs predominantly induce translational repression due to imperfect pairing to their target mRNA, siRNAs often form a perfect duplex with their target and therefore direct the cleavage of the target mRNAs at the site of complementarity.

Figure 1 schematically summarizes the RNAi machinery of the host cell.

\section{Potential therapeutic targets for RNA interference}

RNAi-based therapy for human cancer is one of the most rapidly progressing applications for virally delivered shRNA [18-20]. Theoretically, when using appropriately designed siRNA, the RNAi machinery can be exploited to silence almost any gene in the genome. Indeed, it has already been reported that synthetic siRNAs are capable of knocking down targets in various diseases in vivo [21-23]. Experimentally tested, effective targets are genes involved in cancer-associated cellular pathways, either oncogenes, particularly fusion oncogenes due to their unique link with certain tumor cells, or anti-apoptotic genes. In addition, genes that play a role in tumor-host interactions, such as factors involved in angiogenesis or innate immunity, and those that mediate resistance to chemo- or radiotherapy are targets for interference $[24,25]$. For instance, cancer disease such as ovarian cancer [26] and bone cancer [27] are currently being investigated and successfully treated with siRNAs in vivo.

A further interesting therapy field is the area of miRNA-caused malignancies. The direct effects of miRNA, which are believed to regulate as many as onethird of all human gene transcripts (or messenger RNAs), are implicated in many human diseases. Using gene therapy to manipulate miRNA levels represents an attractive new approach for controlling gene expression and identifying targeted and effective therapeutics [28]. An important role for miRNAs in cancer pathogenesis has emerged over the last few years, and many reports reveal numerous examples linking dysregulated expression of miRNAs to cancer $[29,30]$. Recent results demonstrated that expression of a single miRNA in vivo can reverse disease progression in a liver cancer model [31]. This opened up a whole new replacement therapy field for cancer treatment using RNAi.

Human pathogenic viruses are also excellent targets for RNAi, because, as exogenous sequences, they are unique in the host, which minimizes off-target side effects due to the treatment. Here, the strategy is to target essential viral genes to prevent viral proliferation. However, one has to keep in mind that some viruses have acquired the ability to counteract anti-viral RNAi. Examples of successful RNAi approaches to combat human pathogenic viruses include targeting Hepatitis B Virus (HBV) $[32,33]$, Human Papilloma Virus [34], Severe Acute Respiratory Syndrome (SARS) Coronavirus [35], and Respiratory Syncytial Virus (RSV) infections [36].

Other therapeutically relevant fields are metabolic diseases, cardiac disorders, human neurodegenerative diseases and inherited genetic diseases. A recently published study showed successful siRNA targeting of PCSK9, a member of the mammalian serine protein convertase family, that typically functions in proteolytic processing and maturation of secretory proteins and was the first family member to be implicated in a dominantly inherited form of hypercholesterolemia [37]. Targeting PCSK9 with siRNA lowered plasma cholesterol and hence offers an auspicious therapeutic approach to 


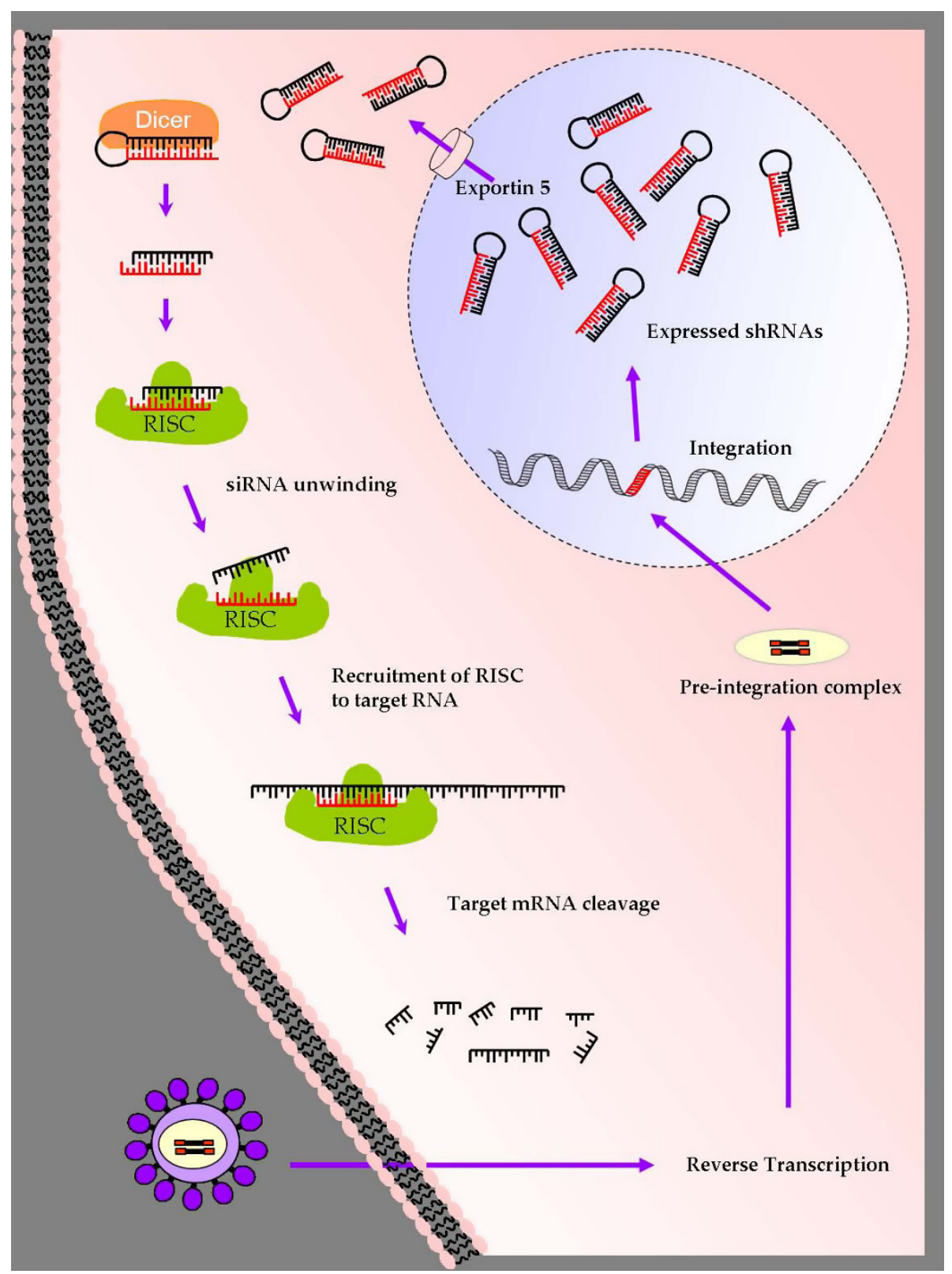

Figure 1 Schematic overview of the mechanism of RNA silencing in the host cell that leads to transcriptional silencing after retroviral delivery of sh/miRNA. Retroviruses (or vectors) deliver therapeutic shRNA-expressing transgenes that integrate into the genome of the host cell and lead to stable shRNA expression. Expressed shRNAs require the activity of endogenous Exportin 5 for nuclear export [129]. Several proteins are recruited and form a dimer with Dicer which receives and subsequently cleaves the dsRNA generating duplex siRNAs with 2 nt 3' overhangs. These siRNAs activate the RNA-induced silencing complex (RISC) which unwinds the RNA and recruits only the guiding strand to target mRNA which is subsequently cleaved and degraded. The figure is schematic, and the Dicer and RISC complexes can vary dependent on cellular process.

controlling this disease. Clinical trials for coronary artery disease are also underway, using an RNA therapeutic agent aimed at silencing one of the genes (c-myc) responsible for causing arteries to reclose after stent insertion (restenosis) [38]. Another study showed almost completely resolved liver fibrosis and prolonged survival in vivo in rats following treatment with synthetic and modified
siRNAs. The efficacy highlighted a new therapeutic potential for reversing human liver cirrhosis [39]. Table 1 provides a rough overview of current clinical trials for siRNA therapeutics.

The first clinical trial conducted using siRNA was aimed at age related macular degeneration (AMD) [40]. As early as 2004, the company Sirna presented the first 
Table 1 Current Clinical Trials for siRNA Therapeutics

\begin{tabular}{llll}
\hline Disease & Mode of administration & Status & Company \\
\hline Age-related macular degeneration (AMD) & Topical & Phase II & Allergan \\
\hline Respiratory syncytial virus (RSV) & Local/direct & Phase II & Alnylam \\
\hline Liver cancer (HCC and others) & Systemic & Phase I & Alnylam \\
\hline Hepatitis B Virus (HBV) & Systemic & Phase I & Nucleonics \\
\hline Solid tumors & Systemic/local & Phase I & Calando Silence Therapeutics AG \\
\hline Acute renal failure & Systemic & Phase I & Quark Pharmaceuticals/Pfizer \\
\hline Diabetic macular edema & Topical & Phase II & Silence/Quark/Pfizer \\
\hline Metastatic melanoma & Local/direct & Phase I & Duke University \\
\hline Pachyonychia congenita & Topical & Phase Ia/b & Transderm \\
\hline High cholesterol & Systemic & Phase I & Tekmira Pharmaceuticals Corporation \\
\hline Asthma & Systemic & Phase II & ZaBeCor Pharmaceuticals \\
\hline HIV & Direct & Phase I/I & Benitec/City of Hope
\end{tabular}

ever clinical data for an RNAi-based drug - the compound AGN-745, formerly Sirna-027 - against AMD [41]. The company OPOKO Health launched the first ever siRNA Phase III trial in 2007 using Bevasiranib, a first-in-class siRNA drug designed to silence the genes producing Vascular Endothelial Growth Factor (VEGF), believed to be largely responsible for vision loss in wet AMD. Unfortunately in March 2009, the phase III trial was terminated ahead of schedule due to a review by an independent data committee, which found that although the drug showed activity, the trial was unlikely to meet its primary endpoint (OPOKO Health, Miami, Florida, press release). One should keep in mind that the clinical trials were performed with unmodified siRNAs and no doubt showed good results, but apparently not convincing enough for human therapy.

Failure of this first clinical phase III study highlights the need for second generation siRNA therapeutics, for example shRNA-expression cassettes, as well as efficient transfer vehicles for these cassettes.

\section{Delivery of interfering RNA}

In principal, there are many different ways to trigger RNAi. Most of the proposed clinical applications of RNAi incorporate chemically synthesized 21 nt siRNA duplexes with 2 nt 3' overhangs. This mode of administration is transient, since intracellular concentrations of the siRNAs are diluted during cell division. Furthermore, duplex siRNAs are negatively charged polymers and therefore do not easily penetrate hydrophobic cellular membranes without assisting carriers. In addition, unprotected and unmodified siRNAs are generally rapidly degraded by serum RNases.

In contrast, intracellularly expressed short hairpin RNAs mediate long-term knock-down of target transcripts for as long as the shRNA is transcribed. Therapy of chronic diseases, for example, requires exactly this - long-term target gene down-regulation. An ideal delivery vehicle should therefore facilitate endosomal/ lysosomal escape and, in the case of shRNA, the payload must penetrate the nuclear membrane. Viruses and vectors derived from them carry out precisely these tasks and have therefore become a major delivery system for shRNA.

RNAi in cells can be induced from intracellularly expressed short hairpin RNAs either by shRNAs or synthetic miRNAs $[2,42,43]$. The basic transcriptional unit of shRNA is sense and antisense sequences connected by a loop of unpaired nucleotides. MiRNA stem loops are typically expressed as part of larger primary transcripts (pri-miRNAs) [44]. Artificial miRNAs more naturally resemble endogenous RNAi substrates and are more amenable to Pol-II transcription and may seem to be more attractive for therapies $[44,45]$. But to date shRNA- and artificial miRNA-based strategies have been compared with conflicting results [46-48] and it seems that the choice is always dependent on the strategy and the desired outcome and has to be figured out experimentally [49].

\section{Viral delivery of shRNA expression cassettes}

Combining RNAi with viral gene therapy vectors is a powerful approach in certain scenarios where spatiotemporal control over gene silencing is highly critical, and/ or where persistent suppression of a target is mandatory for success. The design of viral RNAi vectors became possible upon discovering that promoter-driven expression of short hairpin RNAs (shRNAs) induces the RNAi machinery [50]. This strategy involves cloning an oligonucleotide containing the siRNA sequence into plasmid or viral vectors to endogenously express shRNA, which is subsequently processed in the cytoplasm to siRNA. Fortunately, shRNA expression cassettes are extremely limited in size, meaning they can be packaged into even 
the smallest known viral vectors. The next section reviews existing viral vector systems.

\section{Adenovirus vectors}

Adenoviruses (AdV) belong to the family of Adenoviridae, and adenoviral vectors are frequently used for experimental gene therapy and $25 \%$ of clinical gene therapy trials currently underway are using adenovirus [51]. Adenoviruses are medium-sized, non-enveloped viruses with a nucleocapsid and a linear dsDNA genome. They are able to replicate in the nucleus of mammalian cells but do not efficiently integrate into the host's genome. AdVs are able to package approximately 8-30 $\mathrm{kb}$ of foreign DNA. Several AdV features are attractive for vector use, including infection of both dividing and non-dividing cells, high levels of transgene expression and the ability to grow to high titers in vitro. There are 53 described serotypes in humans, and AdVs are responsible for $5-10 \%$ of upper respiratory infections in children and many infections in adults. Hence seropositivity to $\mathrm{AdV}$ is frequently observed, a drawback for gene therapy using AdV. Entry of adenoviruses and their vectors into cells involves two sets of interactions between the virus and the host cell. First, the viral fiber protein binds to the cell receptor, either CD46 for group B human adenovirus serotypes or the coxsackievirus adenovirus receptor (CAR) for all other serotypes. The initial binding is followed by a secondary interaction, where the penton base protein interacts with an integrin, resulting in entry of virions into the host cell [52]. Adenoviral vectors exhibit no clear tissue tropism, however the relevant surface receptors are often absent in the tissue of interest (especially in tumor cells).

In connection with RNAi therapy the large packaging capacity of a gutless adenovirus vector could be a problem for small shRNA cassettes, since they might jeopardize genetic vector stability [53]. A further disadvantage of $\mathrm{AdV}$ vectors is the problem of repeated administration, which can trigger a strong immune response, potentially limiting their effectiveness in certain therapeutic settings. Additionally, the frequently described liver toxicity $[54,55]$ makes adenoviral vectors unsuitable, or at least to be handled with care in human therapy.

Today, adenoviral vectors are a common delivery method to introduce shRNA-expression cassettes into target cells in vitro and are commercially available. Several publications report the use of adenoviral vectors for transducing RNAi-based therapies in vivo. The first study employing an adenoviral vector for in vivo RNAi was published in 2002 for an application in the central nervous system [42]. These data validate the outstanding promise of oncolytic adenoviral vectors for tumorrestricted shRNA expression [56], although still with the limitations mentioned above. Different reviews have summarized adenoviral shRNA delivery in great detail (e.g. [57]) and the interested reader should refer to them.

\section{Adeno-associated virus vectors}

Adeno-associated viral (AAV) vectors have also been tested in clinical studies in multiple tissues [58]. AAV is one of the smallest viruses and belongs to the genus Dependovirus and the family Parvoviridae. It has a small, single-stranded DNA genome $(4.8 \mathrm{~kb})$ and is apathogenic in humans (at least according to current knowledge). The genome contains only two genes, which can be replaced with foreign ones, leaving only the terminal ITRs to allow high-level expression of the insert. However, the $5 \mathrm{~kb}$ packaging limit of AAV is still sufficient to accommodate at least eight individual shRNA expression cassettes $[19,59]$. The virus is replication-defective and until recently required adenovirus for replication and production of vectors. New methods for producing recombinant AAV using single adenoviral genes have made adenoviral co-infection of AAV-producing cells dispensable [60]. Although wild-type AAV preferentially integrates within a specific region of human chromosome 19, recombinant AAV is engineered to be inefficient in integration since it lacks the AAV Rep protein $[61,62]$.

In contrast to adenovirus, pseudotyping of AAV permits entry retargeting, allowing delivery of the shRNA cassette to specific cells or tissues [63]. Furthermore, AAV-vectors show only low reactivity with cellular immune responses.

To date, several reports have already described the development of AAV vectors delivering and expressing anti-tumor shRNAs in vitro as well as in small animal models. One study exploited AAV expressing shRNAs against Hec1 (highly expressed in cancer 1) [64]. Repeated intratumoral administration caused anti-proliferative and pro-apoptotic effects in tumor cells. Another recent study dealt with shRNA mediated down-regulation of the androgen receptor (AR). Systemic delivery of recombinant AAV vectors stably expressing shRNA against the AR gene eliminated prostate xenografts in nude mice [65]. Details and further possible applications for AAV in shRNA delivery can be found elsewhere (e.g. [66,67]).

Both adenoviral (AdV) and adeno-associated virus (AAV) vectors are non-integrating and therefore pose only minimal risks of insertional mutagenesis. At the same time, this may represent a negative aspect since the genetic information is less stably conserved and may be lost during repetitive cell division. So, although these vectors transduce both dividing and non-dividing cells allowing very efficient gene transfer, they are inadequate for long-term gene replacement therapy. 


\section{Retrovirus vectors}

The use of gene delivery vectors based on retroviruses was introduced in the early $1980 \mathrm{~s}$ by Mann et al. [68]. These single-stranded (ss)RNA viruses belong to the family of Retroviridae and replicate through a doublestranded DNA intermediate. They integrate their genomes stably into the host cell DNA allowing long-term expression of inserted therapeutic genes. The subfamily of Orthoretrovirinae comprises different genii, for example the simplest Gammaretroviruses (e.g. MLV) and the more complex Lentiviruses (e.g. HIV). The viral genome is approximately $10 \mathrm{~kb}$, containing at least three genes: gag (coding for core proteins), pol (coding for reverse transcriptase) and $e n v$ (coding for the viral envelope protein). Complex retroviruses encode a number of accessory proteins that are involved in regulating viral replication or the host cell response to the virus. At each end of the genome, long terminal repeats (LTRs) contain promoter/enhancer regions and sequences involved in integration. In addition there are sequences required for packaging the viral RNA (psi $\Psi^{+}$).

Retroviral entry and genome integration do not require viral protein synthesis; therefore all viral genes in the vector genome can be replaced with foreign sequences. Vector particles are produced by packaging cell lines that provide the viral proteins in trans. These cells release vector genomes packaged into infectious particles that are free from contaminating helper virus and replication-competent recombinant virus. Hence, no viral proteins are produced after transduction, avoiding inducing adverse effects or immune responses against the vector particle, and preventing subsequent spread of the vector.

When exiting the cell, retroviruses and their vectors acquire cell-derived lipid bilayers containing inserted glycoproteins (Env) by budding from the host cell membrane. The Env protein mediates attachment and fusion between the next host cell membrane and viral membrane, which results in release of the viral capsid particle containing the genetic material into the cytoplasm. This plays a central role in targeting retroviral entry to target cells, since Env interacts with a specific cellular protein and accordingly determines viral tropism.

Altering the $e n v$ gene or its product is one possible way to manipulate the target cell range [69-72] and increase the vector's safety. The most successful approach to enhancing safety for tumor therapy is engineering protease-activated Env proteins. In this system, viruses remain non-infectious until Env becomes activated via cleavage by a secreted or membrane-bound protease that recognizes an engineered protease substrate $[73,74]$. More detailed information can be found elsewhere [75-78]. Selective infection of tumor cells combined with transfer of anti-tumoral sh/mi/siRNAs is an attractive strategy for cancer therapy, and is the focus of current research. Several strategies have been explored, and summaries can be found elsewhere [79].

The use of retroviral vectors for efficiently introducing shRNA expression cassettes into target cells has been exploited for many years now. Retroviruses were among the first vectors used as transfer vehicles for hairpinRNA expressing plasmids. Brummelcamp et al. [50] used retroviruses and highlighted the extreme specificity of the RNAi concept, fanning interest in using RNAi for therapeutic applications and cancer therapy. A number of publications followed, using retroviral vectors based on Murine Leukemia Virus (MLV) as transfer vehicles for shRNA-expression cassettes. The most prominent were the works of Paddison et al. [80] and Berns et al. [81] both published in 2004. The groups generated retrovirus-based shRNA expression libraries capable of targeting around a third of all human genes. These libraries showed promise in gene analysis and discovery since they enabled large-scale genetic screens and offered a tool for identifying genes involved in specific biological processes.

Other work followed $[48,82,83]$ applying retrovirally delivered shRNA for high throughput screening. More detailed views on pioneering experiments can be found elsewhere (e.g. [18]), and retroviruses are still currently being used as transfer vehicles for shRNA [84,85].

One recent study reported prolonged suppression of productive HIV-1 infection in a T-cell line (Molt-4) by a retrovirally (MLV) delivered shRNA targeting a sequence located within the NF- $\kappa \mathrm{B}$ binding motif of the HIV-1 promoter. HIV-1 expression in the shRNA expressing CD4(+) T-cell line was suppressed for 1 year [86].

\section{Lentivirus vectors}

Lentiviruses (LV) constitute a subclass of retroviruses and also carry two copies of a single-stranded RNA genome in an enveloped capsid. Among the different species in the genus lentivirinae, the most prominent is the Human Immunodeficiency Virus (HIV), as well as others such as the Feline Immunodeficiency Virus (FIV) or Simian Immunodeficiency Virus (SIV).

In contrast to the retroviral vectors above mentioned, lentiviral vectors are capable of transducing dividing and non-dividing cells (e.g. neurons), which makes them preferred candidate vectors for nervous system applications. Lentiviral vectors can accommodate large (up to $7.5 \mathrm{~kb}$ ) amounts of DNA [87], are less immunogenic than adenoviral vectors and are mostly used for local applications as well as for ex vivo gene therapy. They are more complex than simple retroviruses, containing additional six proteins, tat, rev, vpr, vpu, nef and vif. Since the native viruses can cause fatal diseases in 
humans, non-replicating viruses are used for transgene expression. Current packaging cells are usually transfected with separate plasmids encoding for an env gene, a transgene construct and a packaging construct supplying the structural and regulatory genes in trans [88].

The most advanced and safest forms are the engineered "self-inactivating" (SIN) vectors. Here, the U3 region of the UTR is deleted, and a heterologous promoter (such as CMV) ensures transcription of the entire vector mRNA. This strategy excludes any risk of recreating replication competent wildtype-like viruses by chance.

Just like the gamma-retroviruses, lentiviral vectors are amenable to pseudotyping. For example, pseudotyping of env with VSV-G broadens tropism and supports uptake into otherwise refractory cells, such as human hematopoietic or embryonic stem cells [89].

Lentiviruses are commonly used as vectors for the transfer of shRNA-expression cassettes. Today, delivery of shRNAs into target cells via lentiviral vectors is so efficient that various companies offer this method for in vitro experiments. During the past 10 years, several adaptations and novel techniques have emerged to improve (conditional) transgene expression, and the assiduous scientist can choose between different wellestablished systems for their experimental setup.

Examples for the use of lentiviral vectors as vector systems for shRNA are innumerable, so here, we will only touch on a few. In many cases, lentiviral vectors have been employed successfully to regulate target genes in the brain after local injection $[42,90,91]$. In an upcoming clinical trial one application of RNAi will involve ex vivo lentiviral vector delivery of an shRNA expression cassette into hematopoietic stem cells collected from patients infected with HIV. The transduced cells must be re-infused into these patients for a therapeutic benefit in vivo [92]. LV have also been used to create transgenic animals, but one drawback is the fact that vectors become silenced after long-term culture [93]. Different reviews give exhaustive surveys in great detail, e.g. [94-97].

\section{Baculovirus}

The insect baculovirus is in its very early testing stages as a possible vector for in vivo use and as vector for shRNA [98]. Reports on baculovirus-delivered shRNA comprise manageable amounts of publications. Vectors based on baculovirus can transport large amounts of genetic data leaving copious space for creative combination of gene therapy and silencing vectors [99]. Furthermore, baculovirus is unable to replicate and express viral proteins in mammalian cells, making the virus a safe gene therapy candidate now in its first developmental stages. Baculovirus-based shRNA expression is currently used to target different viral infections, for example HCV replication $[100,101]$ as well as Influenza virus $A$ and $B$ [102]. However, the effects are transient, since a major limitation of baculoviral transduction vectors is the short duration of transgene expression. There are ways to overcome this, for example by inserting Epstein-Barr Virus sequences into the baculovirus vector to improve long-term expression [103]. There is still a long way to go before the promising results find their way into human therapy trials.

\section{Replicating Viruses}

Effective gene-based therapies not only require efficient delivery of therapeutic genes to targeted mammalian cells but also continuous gene expression. Now, the realization that conventional gene therapy approaches have yet to deliver significant therapeutic benefit for cancer treatment, combined with advances over the past 25 years, has re-ignited interest in using replicating viruses. The big advantage of replicating viruses in contrast to replication-defective vectors is that they are able to spread through tumor tissue by viral propagation. In this setting, each transduced/infected tumor cell becomes a virusproducing cell, thereby sustaining further infection beyond the initial inoculum. This idea led to a novel cancer therapy: oncolytic virotherapy. Recent advances in molecular biology have allowed the design of several genetically modified viruses, such as Adenovirus $[104,105]$ and Herpes Simplex Virus [106-108] that specifically replicate in and kill tumor cells. Also Reovirus [109,110], Poliovirus [111,112], Paramyxovirus [113], Vaccinia Virus [114-117] and Vesticular Stomatitis Virus [118] are being exploited. These viruses possess intrinsic oncolytic activity since infection finally leads to host cell death. In contrast, LV and MLV have no oncolytic activity, and shRNA-expression cassettes are used to fulfill effector functions.

\section{Conditionally replicating lentiviruses}

Fully replicating lentiviruses such as HIV, due to their calamitous risk to benefit ratios in healthy patients, are not up for discussion as gene transfer vehicles. However, in already infected HIV-1-positive patients gene transfer using conditionally replicating lentiviral vectors are under consideration $[119,120]$. A strategy based on exploiting an HIV-based lentiviral vector carrying an antisense sequence targeting HIV to treat HIV infection has entered clinical trials. This trial is evaluating a conditionally replicating HIV-1-derived vector pseudotyped with VSV-G expressing an 937-base antisense gene against the HIV envelope [120]. The novel idea is retaining the full HIV LTRs in the vector, resulting in upregulated expression of the antisense upon wildtype HIV infection of the cell. The study showed improved cellular responses to HIV in four out of five subjects, and 
three experienced improvement in their $\mathrm{T}$ cell memory responses.

As opposed to the antisense-strategy used above, another group is studying shRNA-expression cassettes as transgenes in replicating HIV-1, using a doxycyclindependent HIV-1 variant [119]. The virus replicated conditionally in the presence of doxycyclin (dox) and efficiently delivered anti-nef shRNAs to those cells susceptible to HIV-1 infection. Dox withdrawal generated cells containing a silently integrated provirus with an active shRNA expression cassette. Removal of nefsequences from the vector genome avoided vector selftargeting but inhibited HIV-1 replication in transduced cells in vitro.

The use of (conditionally) replicating lentiviral vectors seems promising in the treatment of HIV-1 infections using shRNA and may prove beneficial for this therapy spectrum.

\section{Replication competent MLV}

Unique among the replicating viruses being developed as oncolytic agents, retroviruses, in particular MLVbased viruses, replicate without immediate lysis of host cells and can maintain viral persistence through stable integration.

Retroviruses have been studied extensively for almost 100 years and the work until now has culminated in the first clinical trials [121] using replicating MLVs in vivo. MLV exhibits tumor selectivity due to its inability to infect quiescent cells and can achieve highly selective and stable gene transfer throughout entire solid tumors in vivo at efficiencies of up to $>99 \%$ even after initial inoculation at MOIs as low as 0.01 [122]. One obstacle to overcome in tumor therapy using replication competent retroviruses is the restricted size for inserted transgenes. The size of the MLV genome is limited to roughly $11 \mathrm{~kb}$ and viral genes cannot be replaced by transgenes.

One possibility to overcome this restriction is engineering MLVs in a semi-replicative setting. The idea is to split the viral genome onto two transcomplementing vectors, each carrying the genetic information for either $\mathrm{gag} / \mathrm{pol}$ or env and/or a transgene. Only together - not alone - these vectors contain the genetic material necessary for replication and vector production upon cell transfection. We and others developed this idea $[71,123,124]$, where the $\mathrm{gag} / \mathrm{pol}$ and env genes are split between two viral genomes. The duo allows co-propagation of two different transgenes, which offers both a back-up therapeutic opportunity, should the effect of the first gene product wane due to developing drug resistance, and a means for vector replication shut off, if the transgene is a suicide gene. The split genomes also enhance the capacity for inserting a therapeutic gene.
We constructed split viral genomes and used fluorescent proteins to visually monitor viral replication of the resulting SRRVs [71].

Replication competent viruses containing the complete genome can also be used to carry transgenes. In 2001, Logg and Kasahara [125] conducted studies testing the insertion capacity of replicating viruses and found that MLVs containing inserts of 1.15 to $1.30 \mathrm{~kb}$ replicated with only slightly attenuated kinetics compared to wildtype and efficiently spread transgenes after in vivo administration.

Many reports describe replicating MLVs for gene therapy using inserted suicide genes [126]. We pioneered replicating MLVs as transfer vehicles for shRNAs to amplify shRNA delivery [127]. Our replicating MLV constructs express shRNA under the control of an RNA pol III promoter [50,128]. Inserting the cassette did not interfere significantly with viral fitness, and vectors were genetically stable and functional in silencing target gene expression. Our results show that replicating MLVs are excellent tools for efficient delivery and expression of shRNAs, have great potential for functional genomics, and might be suitable for in vivo cancer gene therapy, if combined with efficient entry targeting. We are currently focusing on in vivo studies using these viruses and look forward to promising results.

\section{Conclusions}

RNAi technology has become a powerful tool and key method for gene therapy in the scientist's hands. Although the effectiveness of RNAi is undoubted, there are still limitations to exploiting the technology properly due to inefficient delivery and distribution of the shRNA-cassettes into the target cells. Focusing on viral delivery of shRNA, we highlighted that viruses and vectors derived from them are excellent candidates to deliver shRNA into the desired tissue or cells. We discussed different methods for viral delivery of shRNA expression cassettes using conventional methods and revealed promising new strategies utilizing replicating retroviruses.

\section{Authors' contributions}

KS and BS contributed equally to conception, design and acquisition of data. Both have been involved in drafting the manuscript and give final approval of the version to be published.

\section{Competing interests}

The authors declare that they have no competing interests.

Received: 11 June 2010 Accepted: 21 September 2010

Published: 21 September 2010

\section{References}

1. Fire A, Xu S, Montgomery MK, Kostas SA, Driver SE, Mello CC: Potent and specific genetic interference by double-stranded RNA in Caenorhabditis elegans. Nature 1998, 391:806-811. 
2. Elbashir SM, Harborth J, Lendeckel W, Yalcin A, Weber K, Tuschl T: Duplexes of 21-nucleotide RNAs mediate RNA interference in cultured mammalian cells. Nature 2001, 411:494-8.

3. Kim VN: MicroRNA biogenesis: coordinated cropping and dicing. Nat ReV Mol Cell Biol 2005, 6:376-385.

4. Echeverri CJ, Beachy PA, Baum B, Boutros M, Buchholz F, Chanda SK, et al: Minimizing the risk of reporting false positives in large-scale RNAi screens. Nat Methods 2006, 3:777-779.

5. Echeverri CJ, Perrimon N: High-throughput RNAi screening in cultured cells: a user's guide. Nat Rev Genet 2006, 7:373-384.

6. Monia BP, Lesnik EA, Gonzalez C, Lima WF, McGee D, Guinosso CJ, et al: Evaluation of 2'-modified oligonucleotides containing 2'-deoxy gaps as antisense inhibitors of gene expression. J Biol Chem 1993, 268:14514-14522.

7. Lubini P, Zurcher W, Egli M: Stabilizing effects of the RNA $2^{\prime}$-substituent: crystal structure of an oligodeoxynucleotide duplex containing 2'-Omethylated adenosines. Chem Biol 1994, 1:39-45.

8. Hutvagner G, Zamore PD: A microRNA in a multiple-turnover RNA enzyme complex. Science 2002, 297:2056-2060.

9. Hutvagner G, Zamore PD: RNAi: nature abhors a double-strand. Curr Opin Genet Dev 2002, 12:225-232.

10. Bartlett DW, Davis ME: Effect of siRNA nuclease stability on the in vitro and in vivo kinetics of siRNA-mediated gene silencing. Biotechnol Bioeng 2007, 97:909-921.

11. Bartlett DW, Davis ME: Insights into the kinetics of siRNA-mediated gene silencing from live-cell and live-animal bioluminescent imaging. Nucleic Acids Res 2006, 34:322-333.

12. Couzin J: Breakthrough of the year. Small RNAs make big splash. Science 2002, 298:2296-7.

13. Bartel DP: MicroRNAs: genomics, biogenesis, mechanism, and function. Cell 2004, 116:281-297.

14. Brodersen $\mathrm{P}$, Voinnet $\mathrm{O}$ : The diversity of RNA silencing pathways in plants. Trends Genet 2006, 22:268-280.

15. Vaucheret $\mathrm{H}$ : Post-transcriptional small RNA pathways in plants: mechanisms and regulations. Genes Dev 2006, 20:759-771.

16. Lee Y, Kim VN: Preparation and analysis of Drosha. Methods Mol Biol 2005, 309:17-28

17. Kim VN: Small RNAs just got bigger: Piwi-interacting RNAs (piRNAs) in mammalian testes. Genes Dev 2006, 20:1993-1997.

18. Chang K, Elledge SJ, Hannon GJ: Lessons from Nature: microRNA-based shRNA libraries. Nat Methods 2006, 3:707-714.

19. Grimm D, Kay MA: Therapeutic short hairpin RNA expression in the liver: viral targets and vectors. Gene Ther 2006, 13:563-575.

20. Subramanya S, Kim SS, Manjunath N, Shankar P: RNA interference-based therapeutics for human immunodeficiency virus HIV-1 treatment: synthetic siRNA or vector-based shRNA? Expert Opin Biol Ther 2010, 10:201-213.

21. de Fougerolles A, Vornlocher HP, Maraganore J, Lieberman J: Interfering with disease: a progress report on siRNA-based therapeutics. Nat Rev Drug Discov 2007, 6:443-453.

22. Cheng JC, Moore TB, Sakamoto KM: RNA interference and human disease. Mol Genet Metab 2003, 80:121-128.

23. van Es HH, Arts GJ: Biology calls the targets: combining RNAi and disease biology. Drug Discov Today 2005, 10:1385-1391.

24. Hanahan D, Weinberg RA: The hallmarks of cancer. Cell 2000, 100:57-70

25. Ellis LM, Hicklin DJ: Resistance to Targeted Therapies: Refining Anticancer Therapy in the Era of Molecular Oncology. Clin Cancer Res 2009, 15:7471-7478.

26. Halder J, Kamat AA, Landen CN Jr, Han LY, Lutgendorf SK, Lin YG, et al: Focal adhesion kinase targeting using in vivo short interfering RNA delivery in neutral liposomes for ovarian carcinoma therapy. Clin Cancer Res 2006, 12:4916-4924.

27. Takeshita F, Minakuchi Y, Nagahara S, Honma K, Sasaki H, Hirai K, et al: Efficient delivery of small interfering RNA to bone-metastatic tumors by using atelocollagen in vivo. Proc Natl Acad Sci USA 2005, 102:12177-12182.

28. Marquez RT, McCaffrey AP: Advances in microRNAs: implications for gene therapists. Hum Gene Ther 2008, 19:27-38.

29. Calin GA, Croce CM: MicroRNA signatures in human cancers. Nat Rev Cancer 2006, 6:857-866

30. Calin GA, Croce CM: MicroRNA-cancer connection: the beginning of a new tale. Cancer Res 2006, 66:7390-7394.
31. Kota J, Chivukula RR, O'Donnell KA, Wentzel EA, Montgomery CL, Hwang HW, et al: Therapeutic microRNA delivery suppresses tumorigenesis in a murine liver cancer model. Cell 2009, 137:1005-1017.

32. Morrissey DV, Lockridge JA, Shaw L, Blanchard K, Jensen K, Breen W, et al: Potent and persistent in vivo anti-HBV activity of chemically modified siRNAs. Nat Biotechnol 2005, 23:1002-1007.

33. Song E, Lee SK, Wang J, Ince N, Ouyang N, Min J, et al: RNA interference targeting Fas protects mice from fulminant hepatitis. Nat Med 2003, 9:347-351.

34. Niu XY, Peng ZL, Duan WQ, Wang H, Wang P: Inhibition of HPV 16 E6 oncogene expression by RNA interference in vitro and in vivo. Int $\mathrm{J}$ Gynecol Cancer 2006, 16:743-751.

35. Li BJ, Tang Q, Cheng D, Qin C, Xie FY, Wei Q, et al: Using siRNA in prophylactic and therapeutic regimens against SARS coronavirus in Rhesus macaque. Nat Med 2005, 11:944-951.

36. Bitko V, Musiyenko A, Shulyayeva O, Barik S: Inhibition of respiratory viruses by nasally administered siRNA. Nat Med 2005, 11:50-55.

37. Abifadel M, Varret M, Rabes JP, Allard D, Ouguerram K, Devillers M, et al: Mutations in PCSK9 cause autosomal dominant hypercholesterolemia. Nat Genet 2003, 34:154-156.

38. Li FY, Cheng NS, Cheng JQ, Mao H, Jiang LS, Li N, et al: Treatment of chronic proliferative cholangitis with c-myc shRNA. World J Gastroenterol 2009, 15:95-101.

39. Sato Y, Murase K, Kato J, Kobune M, Sato T, Kawano Y, et al: Resolution of liver cirrhosis using vitamin A-coupled liposomes to deliver siRNA against a collagen-specific chaperone. Nat Biotechnol 2008, 26:431-442.

40. McFarland TJ, Zhang Y, Appukuttan B, Stout JT: Gene therapy for proliferative ocular diseases. Expert Opin Biol Ther 2004, 4:1053-1058.

41. Check E: A crucial test. Nat Med 2005, 11:243-244.

42. Xia $H$, Mao $Q$, Paulson $H L$, Davidson BL: siRNA-mediated gene silencing in vitro and in vivo. Nat Biotechnol 2002, 20:1006-1010.

43. Zeng Y, Wagner EJ, Cullen BR: Both natural and designed micro RNAs can inhibit the expression of cognate mRNAs when expressed in human cells. Mol Cell 2002, 9:1327-1333.

44. Cai $X$, Hagedorn $\mathrm{CH}$, Cullen BR: Human microRNAs are processed from capped, polyadenylated transcripts that can also function as mRNAs. RNA 2004, 10:1957-1966.

45. Chung KH, Hart CC, Al Bassam S, Avery A, Taylor J, Patel PD, et al: Polycistronic RNA polymerase II expression vectors for RNA interference based on BIC/miR-155. Nucleic Acids Res 2006, 34:e53.

46. Li L, Lin X, Khvorova A, Fesik SW, Shen Y: Defining the optimal parameters for hairpin-based knockdown constructs. RNA 2007, 13:1765-1774.

47. Boden D, Pusch O, Silbermann R, Lee F, Tucker L, Ramratnam B: Enhanced gene silencing of HIV-1 specific siRNA using microRNA designed hairpins. Nucleic Acids Res 2004, 32:1154-1158.

48. Silva JM, Li MZ, Chang K, Ge W, Golding MC, Rickles RJ, et al: Secondgeneration shRNA libraries covering the mouse and human genomes. Nat Genet 2005, 37:1281-1288.

49. Liu YP, Vink MA, Westerink JT, Ramirez dA, Konstantinova P, Ter Brake O, et al: Titers of lentiviral vectors encoding shRNAs and miRNAs are reduced by different mechanisms that require distinct repair strategies. RNA 2010, 16:1328-1339.

50. Brummelkamp TR, Bernards R, Agami R: A System for Stable Expression of Short Interfering RNAs in Mammalian Cells. Science 2002, 296:550-3.

51. Relph $\mathrm{KL}$, Harrington $\mathrm{KJ}$, Pandha $\mathrm{H}$ : Adenoviral strategies for the gene therapy of cancer. Semin Oncol 2005, 32:573-582.

52. $W u E$, Nemerow GR: Virus yoga: the role of flexibility in virus host cell recognition. Trends Microbiol 2004, 12:162-169.

53. Huang B, Schiefer J, Sass C, Landwehrmeyer GB, Kosinski CM, Kochanek S: High-capacity adenoviral vector-mediated reduction of huntingtin aggregate load in vitro and in vivo. Hum Gene Ther 2007, 18:303-311.

54. Descamps D, Benihoud K: Two key challenges for effective adenovirusmediated liver gene therapy: innate immune responses and hepatocytespecific transduction. Curr Gene Ther 2009, 9:115-127.

55. Kuhlmann KF, Gouma DJ, Wesseling JG: Adenoviral gene therapy for pancreatic cancer: where do we stand? Dig Surg 2008, 25:278-292.

56. Yoo JY, Kim JH, Kwon YG, Kim EC, Kim NK, Choi HJ, et al: VEGF-specific short hairpin RNA-expressing oncolytic adenovirus elicits potent inhibition of angiogenesis and tumor growth. Mol Ther 2007, 15:295-302.

57. Li X, Liu X, Li CY, Ding Y, Chau D, Li G, et al: Recombinant adenoassociated virus mediated RNA interference inhibits metastasis of 
nasopharyngeal cancer cells in vivo and in vitro by suppression of Epstein-Barr virus encoded LMP-1. Int J Oncol 2006, 29:595-603.

58. Koerber JT, Jang JH, Schaffer DV: DNA shuffling of adeno-associated virus yields functionally diverse viral progeny. Mol Ther 2008, 16:1703-1709.

59. Grimm D, Pandey K, Kay MA: Adeno-associated virus vectors for short hairpin RNA expression. Methods Enzymol 2005, 392:381-405.

60. Matsushita T, Elliger S, Elliger C, Podsakoff G, Villarreal L, Kurtzman GJ, et al: Adeno-associated virus vectors can be efficiently produced without helper virus. Gene Ther 1998, 5:938-945.

61. Tenenbaum L, Lehtonen E, Monahan PE: Evaluation of risks related to the use of adeno-associated virus-based vectors. Curr Gene Ther 2003, 3:545-565.

62. Tal J: Adeno-associated virus-based vectors in gene therapy. J Biomed Sci 2000, 7:279-291.

63. Grimm D, Kay MA: From virus evolution to vector revolution: use of naturally occurring serotypes of adeno-associated virus (AAV) as novel vectors for human gene therapy. Curr Gene Ther 2003, 3:281-304.

64. Li L, Yang L, Scudiero DA, Miller SA, Yu ZX, Stukenberg PT, et al: Development of recombinant adeno-associated virus vectors carrying small interfering RNA (shHec1)-mediated depletion of kinetochore Hec1 protein in tumor cells. Gene Ther 2007, 14:814-827

65. Sun A, Tang J, Terranova PF, Zhang X, Thrasher JB, Li B: Adeno-associated virus-delivered short hairpin-structured RNA for androgen receptor gene silencing induces tumor eradication of prostate cancer xenografts in nude mice: A preclinical study. Int I Cancer 2010, 1;126(3):764-74.

66. Park K, Kim WJ, Cho YH, Lee YI, Lee H, Jeong S, et al: Cancer gene therapy using adeno-associated virus vectors. Front Biosci 2008, 13:2653-2659.

67. McCaffrey AP: RNA interference inhibitors of hepatitis B virus. Ann N Y Acad Sci 2009, 1175:15-23.

68. Mann R, Mulligan RC, Baltimore D: Construction of a retrovirus packaging mutant and its use to produce helper-free defective retrovirus. Cell 1983, 33:153-159.

69. Haynes C, Erlwein O, Schnierle BS: Modified envelope glycoproteins to retarget retroviral vectors. Curr Gene Ther 2003, 3:405-10.

70. Erlwein O, Buchholz CJ, Schnierle BS: The proline-rich region of the ecotropic Moloney murine leukaemia virus envelope protein tolerates the insertion of the green fluorescent protein and allows the generation of replication-competent virus. J Gen Virol 2003, 84:369-73.

71. Sliva K, Erlwein O, Bittner A, Schnierle BS: Murine leukemia virus (MLV) replication monitored with fluorescent proteins. Virol J 2004, 1:14.

72. Sliva K, Schnierle BS: Targeting retroviral vector entry by host range extension. Gen Ther Mol Biol 2004, 8:335-342.

73. Duerner LJ, Schwantes A, Schneider IC, Cichutek K, Buchholz CJ: Cell entry targeting restricts biodistribution of replication-competent retroviruses to tumour tissue. Gene Ther 2008, 15:1500-1510.

74. Szecsi J, Drury R, Josserand V, Grange MP, Boson B, Hartl I, et al: Targeted retroviral vectors displaying a cleavage site-engineered hemagglutinin (HA) through HA-protease interactions. Mol Ther 2006, 14:735-744.

75. Lavillette D, Russell SJ, Cosset FL: Retargeting gene delivery using surfaceengineered retroviral vector particles. Curr Opin Biotechnol 2001, 12:461-6.

76. Cosset FL, Russell SJ: Targeting retrovirus entry. Gene Ther 1996, 3:946-56.

77. Russell SJ, Cosset FL: Modifying the host range properties of retroviral vectors. J Gene Med 1999, 1:300-11.

78. Frecha C, Szecsi J, Cosset FL, Verhoeyen E: Strategies for targeting lentiviral vectors. Curr Gene Ther 2008, 8:449-460.

79. Sandrin V, Russell SJ, Cosset FL: Targeting retroviral and lentiviral vectors. Curr Top Microbiol Immunol 2003, 281:137-78.

80. Paddison PJ, Silva JM, Conklin DS, Schlabach M, Li M, Aruleba S, et al: A resource for large-scale RNA-interference-based screens in mammals. Nature 2004, 428:427-431

81. Berns K, Hijmans EM, Mullenders J, Brummelkamp TR, Velds A, Heimerikx M, et al: A large-scale RNAi screen in human cells identifies new components of the p53 pathway. Nature 2004, 428:431-437.

82. Silva JM, Mizuno H, Brady A, Lucito R, Hannon GJ: RNA interference microarrays: high-throughput loss-of-function genetics in mammalian cells. Proc Natl Acad Sci USA 2004, 101:6548-6552.

83. Stegmeier F, Hu G, Rickles RJ, Hannon GJ, Elledge SJ: A lentiviral microRNA-based system for single-copy polymerase II-regulated RNA interference in mammalian cells. Proc Natl Acad Sci USA 2005, 102:13212-13217.
84. Schlabach MR, Luo J, Solimini NL, Hu G, Xu Q, Li MZ, et al: Cancer proliferation gene discovery through functional genomics. Science 2008, 319:620-624.

85. Silva JM, Marran K, Parker JS, Silva J, Golding M, Schlabach MR, et al: Profiling essential genes in human mammary cells by multiplex RNAi screening. Science 2008, 319:617-620

86. Yamagishi M, Ishida T, Miyake A, Cooper DA, Kelleher AD, Suzuki K, et al: Retroviral delivery of promoter-targeted shRNA induces long-term silencing of HIV-1 transcription. Microbes Infect 2009, 11:500-508.

87. al Yacoub N, Romanowska M, Haritonova N, Foerster J: Optimized production and concentration of lentiviral vectors containing large inserts. J Gene Med 2007, 9:579-584.

88. Naldini L, Blomer U, Gage FH, Trono D, Verma IM: Efficient transfer, integration, and sustained long-term expression of the transgene in adult rat brains injected with a lentiviral vector. Proc Natl Acad Sci USA 1996, 93:11382-11388.

89. Chang $A H$, Sadelain M: The genetic engineering of hematopoietic stem cells: the rise of lentiviral vectors, the conundrum of the Itr, and the promise of lineage-restricted vectors. Mol Ther 2007, 15:445-456.

90. Dittgen T, Nimmerjahn A, Komai S, Licznerski P, Waters J, Margrie TW, et al: Lentivirus-based genetic manipulations of cortical neurons and their optical and electrophysiological monitoring in vivo. Proc Natl Acad SCi USA 2004, 101:18206-18211.

91. Bahi A, Boyer F, Kolira M, Dreyer JL: In vivo gene silencing of CD81 by lentiviral expression of small interference RNAs suppresses cocaineinduced behaviour. J Neurochem 2005, 92:1243-1255.

92. Morris KV, Rossi JJ: Lentiviral-mediated delivery of siRNAs for antiviral therapy. Gene Ther 2006, 13:553-558.

93. Hofmann A, Kessler B, Ewerling S, Kabermann A, Brem G, Wolf E, et al: Epigenetic regulation of lentiviral transgene vectors in a large animal model. Mol Ther 2006, 13:59-66.

94. Manjunath N, Wu H, Subramanya S, Shankar P: Lentiviral delivery of short hairpin RNAs. Adv Drug Deliv Rev 2009, 61:732-745.

95. Singer O, Verma IM: Applications of lentiviral vectors for shRNA delivery and transgenesis. Curr Gene Ther 2008, 8:483-488.

96. Sumimoto H, Kawakami Y: Lentiviral vector-mediated RNAi and its use for cancer research. Future Oncol 2007, 3:655-664.

97. Bos TJ, De Bruyne E, Heirman C, Vanderkerken K: In search of the most suitable lentiviral shRNA system. Curr Gene Ther 2009, 9:192-211.

98. Ong ST, Li F, Du J, Tan YW, Wang S: Hybrid cytomegalovirus enhancer-h1 promoter-based plasmid and baculovirus vectors mediate effective RNA interference. Hum Gene Ther 2005, 16:1404-1412.

99. Li CX, Parker A, Menocal E, Xiang S, Borodyansky L, Fruehauf JH: Delivery of RNA interference. Cell Cycle 2006, 5:2103-2109.

100. Suzuki H, Tamai N, Habu Y, Chang MO, Takaku H: Suppression of hepatitis C virus replication by baculovirus vector-mediated short-hairpin RNA expression. FEBS Lett 2008, 582:3085-3089.

101. Suzuki H, Kaneko H, Tamai N, Miyano-Kurosaki N, Hashimoto K, Shimotohno K, et al: Suppression of HCV RNA replication by baculovirusmediated shRNA expression. Nucleic Acids Symp Ser (Oxf) 2005, 339-340.

102. Suzuki H, Saitoh H, Suzuki T, Takaku H: Inhibition of influenza virus by baculovirus-mediated shRNA. Nucleic Acids Symp Ser (Oxf) 2009, 287-288.

103. Suzuki H, Matsumoto N, Suzuki T, Chang MO, Takaku H: Stable replication of the EBNA1/OriP-mediated baculovirus vector and its application to anti-HCV gene therapy. Virol J 2009, 6:156.

104. Habib NA, Sarraf CE, Mitry RR, Havlik R, Nicholls J, Kelly M, et al: E1Bdeleted adenovirus (d11520) gene therapy for patients with primary and secondary liver tumors. Hum Gene Ther 2001, 12:219-226.

105. Sagawa T, Takahashi M, Sato T, Sato Y, Lu Y, Sumiyoshi T, et al: Prolonged survival of mice with multiple liver metastases of human colon cancer by intravenous administration of replicable E1B-55K-deleted adenovirus with E1A expressed by CEA promoter. Mol Ther 2004, 10:1043-1050.

106. Kooby DA, Carew JF, Halterman MW, Mack JE, Bertino JR, Blumgart LH, et al: Oncolytic viral therapy for human colorectal cancer and liver metastases using a multi-mutated herpes simplex virus type-1 (G207). FASEB J 1999, 13:1325-1334.

107. Reinblatt $\mathrm{M}$, Pin RH, Fong $\mathrm{Y}$ : Carcinoembryonic antigen directed herpes viral oncolysis improves selectivity and activity in colorectal cancer. Surgery 2004, 136:579-584. 
108. Reinblatt M, Pin RH, Federoff HJ, Fong Y: Utilizing tumor hypoxia to enhance oncolytic viral therapy in colorectal metastases. Ann Surg 2004, 239:892-899.

109. Zwiebel JA: Cancer gene and oncolytic virus therapy. Semin Oncol 2001, 28:336-343.

110. Figova K, Hrabeta J, Eckschlager T: Reovirus - possible therapy of cancer. Neoplasma 2006, 53:457-462.

111. Khromykh AA: Replicon-based vectors of positive strand RNA viruses. Curr Opin Mol Ther 2000, 2:555-569.

112. Toyoda H, Yin J, Mueller S, Wimmer E, Cello J: Oncolytic treatment and cure of neuroblastoma by a novel attenuated poliovirus in a novel poliovirus-susceptible animal model. Cancer Res 2007, 67:2857-2864.

113. Bell JC, Garson KA, Lichty BD, Stojdl DF: Oncolytic viruses: programmable tumour hunters. Curr Gene Ther 2002, 2:243-254.

114. Thorne SH: Design and testing of novel oncolytic vaccinia strains. Methods Mol Biol 2009, 542:635-647.

115. Kim-Schulze S, Kaufman HL: Gene therapy for antitumor vaccination. Methods Mol Biol 2009, 542:515-527.

116. Kirn DH, Thorne SH: Targeted and armed oncolytic poxviruses: a novel multi-mechanistic therapeutic class for cancer. Nat Rev Cancer 2009, 9:64-71

117. Gnant MF, Puhlmann M, Alexander HR Jr, Bartlett DL: Systemic administration of a recombinant vaccinia virus expressing the cytosine deaminase gene and subsequent treatment with 5 -fluorocytosine leads to tumor-specific gene expression and prolongation of survival in mice. Cancer Res 1999, 59:3396-3403.

118. Lichty BD, Stojdl DF, Taylor RA, Miller L, Frenkel I, Atkins H, et al: Vesicular stomatitis virus: a potential therapeutic virus for the treatment of hematologic malignancy. Hum Gene Ther 2004, 15:821-831.

119. Westerhout EM, Vink M, Joost Haasnoot PC, Das AT, Berkhout B: A conditionally replicating HIV-based vector that stably expresses an antiviral shRNA against HIV-1 replication. Mol Ther 2006, 14(2):268-75.

120. Levine BL, Humeau LM, Boyer J, MacGregor RR, Rebello T, Lu X, et al: Gene transfer in humans using a conditionally replicating lentiviral vector. Proc Natl Acad Sci USA 2006, 103:17372-17377.

121. De Souza AT, Dai X, Spencer AG, Reppen T, Menzie A, Roesch PL, et al: Transcriptional and phenotypic comparisons of Ppara knockout and siRNA knockdown mice. Nucleic Acids Res 2006, 34:4486-4494.

122. Tai CK, Kasahara N: Replication-competent retrovirus vectors for cancer gene therapy. Front Biosci 2008, 13:3083-3095.

123. Trajcevski S, Solly SK, Frisen C, Trenado A, Cosset FL, Klatzmann D: Characterization of a semi-replicative gene delivery system allowing propagation of complementary defective retroviral vectors. I Gene Med 2005, 7:276-287.

124. Qiao J, Moreno J, Sanchez-Perez L, Kottke T, Thompson J, Caruso M, et al: VSV-G pseudotyped, MuLV-based, semi-replication-competent retrovirus for cancer treatment. Gene Ther 2006, 13(20):1457-70.

125. Logg CR, Logg A, Tai CK, Cannon PM, Kasahara N: Genomic stability of murine leukemia viruses containing insertions at the Env-3' untranslated region boundary. J Virol 2001, 75:6989-98.

126. Hiraoka K, Kimura T, Logg CR, Tai CK, Haga K, Lawson GW, et al: Therapeutic efficacy of replication-competent retrovirus vector-mediated suicide gene therapy in a multifocal colorectal cancer metastasis model. Cancer Res 2007, 67:5345-5353.

127. Sliva K, Schnierle BS: Stable integration of a functional shRNA expression cassette into the murine leukemia virus genome. Virology 2006, 351:218-25.

128. Rubinson DA, Dillon CP, Kwiatkowski AV, Sievers C, Yang L, Kopinja J, et al: A lentivirus-based system to functionally silence genes in primary mammalian cells, stem cells and transgenic mice by RNA interference. Nat Genet 2003, 33:401-406.

129. Yi R, Doehle BP, Qin Y, Macara IG, Cullen BR: Overexpression of exportin 5 enhances RNA interference mediated by short hairpin RNAs and microRNAs. RNA 2005, 11:220-226.

doi:10.1186/1743-422X-7-248

Cite this article as: Sliva and Schnierle: Selective gene silencing by viral delivery of short hairpin RNA. Virology Journal 2010 7:248.

\section{Submit your next manuscript to BioMed Central and take full advantage of:}

- Convenient online submission

- Thorough peer review

- No space constraints or color figure charges

- Immediate publication on acceptance

- Inclusion in PubMed, CAS, Scopus and Google Scholar

- Research which is freely available for redistribution 